\title{
Efeito da redução da proteína bruta da ração para suínos mantidos em termoneutralidade
}

\author{
Effect of gross protein reduction in feed for swine kept in thermoneutrality
}

\author{
Melissa Selaysim DI CAMPOS ${ }^{1 *}$, Luiz Roberto Queiroz de Abreu SODRÉ2, \\ André Artin MACHADO ${ }^{2}$, Holmer SAVASTANO JÚNIOR ${ }^{3}$
}

\begin{abstract}
Resumo
Este experimento teve como objetivo avaliar a influência da redução da proteína bruta (PB) e suplementação de aminoácidos sintéticos sobre o desempenho de suínos machos castrados mantidos em ambiente termoneutro ( $24^{\circ} \mathrm{C}$ ). Foram utilizados 80 leitões mestiços (Landrace $\mathrm{x}$ Large White) com peso médio inicial de $9 \mathrm{~kg}$ e idade média de 23 dias. Os animais foram distribuídos em um delineamento inteiramente casualizado, com cinco tratamentos $(18,17,16,15$ e 14\% PB), oito repetições e dois animais por unidade experimental. As rações experimentais foram fornecidas à vontade até o final do experimento, quando os animais atingiram o peso médio de $23 \mathrm{~kg}$ ( 63 dias). A temperatura e a umidade relativa média no interior do galpão foram de $24^{\circ} \mathrm{C}$ e $78,7 \%$, respectivamente. O Índice de Temperatura de Globo e Umidade (ITGU) calculado no período foi de 70,4. Não foi observado efeito significativo na redução do nível de proteína bruta da ração sobre as variáveis de desempenho (consumo de ração, ganho de peso e conversão alimentar). Os tratamentos influenciaram os pesos absoluto e relativo do estômago e o peso absoluto do intestino, sendo os maiores valores observados em animais que receberam a ração com maior nível de proteína bruta. Concluiuse que o nível de PB da ração pode ser reduzido de 18 para 14\%, sem prejudicar o desempenho de suínos machos de 9 a 23 kg mantidos em ambiente termoneutro, desde que esta ração seja devidamente suplementada com aminoácidos essenciais limitantes.
\end{abstract}

Palavras-chave: ambiente termoneutro; aminoácidos; desempenho de suínos; nutrição animal.

\begin{abstract}
This experiment aimed at evaluating the influence of the reduction of gross protein (GP) and the supplementation of synthetic amino acids on the performance of castrated male swines kept in an environment of thermoneutrality $\left(24^{\circ} \mathrm{C}\right)$. Eighty cross-bred piglets (Landrace $\mathrm{X}$ Large White) were used, with an initial average weight of $9 \mathrm{~kg}$ and an average age of 23 days. The animals were distributed in a randomized design, of five treatments $(18,17,16,15$ and $14 \%$ GP), eight repetitions and two animals in each experimental area. The experimental feed was supplied ad libitum until the end of the experiment, when the animals reached $23 \mathrm{~kg}$ average weight (63 days). The temperature and average relative humidity inside the shed were $24^{\circ} \mathrm{C}$ and $78.7 \%$, respectively. The Globe Temperature and Humidity Index calculated for the period was 70.4. No significant effect of the reduction of the gross protein level in the feed was observed on the performance variables (feed consumption, weight gained and dietary conversion). The treatments exhibited an effect on the absolute and relative stomach weight and on the absolute intestine weight, where the highest values were observed for the animals that received the feed with the highest gross protein levels. It was concluded that the GP level of the feed can be reduced from 18 to $14 \%$, without harm to the performance of male swine from 9 to $23 \mathrm{~kg}$ kept in an environment of thermoneutrality, as long as adequately supplemented with limiting essential amino acids.

Keywords: thermoneutral environment; amino acids; swine performance; animal nutrition.
\end{abstract}

\section{Introdução}

Uma maneira de reduzir a excreção de nitrogênio é diminuir a concentração de proteína da ração suplementando-a com aminoácidos para atender as demandas para a síntese protéica, assegurando assim maior eficiência na utilização dos nutrientes e produtividade dos suínos (ANDRIGUETO et al., 1983). Entretanto, de acordo com Figueroa, Lewis e Miller (2000), a redução drástica do nível de proteína bruta na ração para suínos em crescimento pode reduzir o desempenho devido ao menor aporte de aminoácidos não essenciais.

As rações utilizadas pelos criadores de suínos no Brasil, à base de milho e farelo de soja e formuladas para atender à exigência dos animais em lisina, contêm quantidades excessivas de outros aminoácidos, resultando em rações com nível protéico acima das suas necessidades. As rações desbalanceadas ou com excesso de aminoácidos representam uma fonte onerosa de energia metabolizável e um problema ambiental, devido à excessiva excreção de nitrogênio nos dejetos dos suínos (PARSONS; BAKER, 1994). Maiores volumes de urina e dejetos foram observados por Pfeiffer et al. (1995) quando os suínos em fase de crescimento foram alimentados com rações contendo níveis elevados de proteína. O suíno tolera altos níveis de proteína na ração, porém, adicionalmente ao acréscimo no

\footnotetext{
Recebido para publicação em 25/8/2005

Aceito para publicação em 25/6/2007 (001598)

Faculdade de Zootecnia e Engenharia de Alimentos - FZEA, Universidade de São Paulo - USP, Rua Henrique Devitte, 1496, Jardim Rosim, CEP 13634-100,

Pirassununga - SP, Brasil, E-mail: melissaselaysim@uol.com.br

${ }^{2}$ Faculdade de Zootecnia e Engenharia de Alimentos - FZEA, Universidade de São Paulo - USP

${ }^{3}$ Departamento de Engenharia de Alimentos, Faculdade de Zootecnia e Engenharia de Alimentos - FZEA, Universidade de São Paulo - USP

${ }^{*}$ A quem a correspondência deve ser enviada
} 
custo de produção, a elevada concentração dietética de proteína tem implicações negativas na produtividade e no meio ambiente. A substituição da proteína dietética pela suplementação de aminoácidos essenciais pode reduzir o impacto ambiental, e as quantidades adicionais de cloro $(\mathrm{Cl})$ fornecidas pela lisina- $\mathrm{HCl}$ podem exercer efeito mínimo sobre o equilíbrio ácido-base do organismo e, conseqüentemente, sobre o desempenho dos animais. Porém, segundo Patience (1990), outros aminoácidos como treonina e triptofano quando adicionados em grandes quantidades às rações, podem propiciar dietas acidogênicas, com efeitos negativos sobre o desempenho. Nesse caso, a correção do equilíbrio ácido-base torna-se imprescindível para garantir a produtividade dos animais.

Outro aspecto importante a ser considerado em um sistema de produção é a temperatura ambiente, sendo um dos principais elementos climáticos não só devido ao efeito que esta tem sobre a intensidade das trocas térmicas, como indiretamente pela influência que exerce sobre os demais componentes do microclima. Segundo Perdomo (1998), a adequação do meio deve ter caráter permanente, independentemente da maior ou menor habilidade genética do suíno. Ferreira et al. (2003) cita como faixa ideal de temperatura para melhor desempenho produtivo e qualidade de carcaça de suínos em crescimento, temperaturas entre 20 e $25^{\circ} \mathrm{C}$.

Este trabalho objetivou avaliar os efeitos da redução na proteína bruta da ração com suplementação de aminoácidos (DL-metionina, L-Lisina $\mathrm{HCl}$ e L-Treonina) sobre o desempenho de suínos machos castrados com pesos variando de 9 a $23 \mathrm{~kg}$, mantidos em ambiente de termoneutralidade.

\section{Material e métodos}

O experimento foi conduzido no Setor de Suinocultura do Departamento de Zootecnia da Fundação do Ensino Superior de Rio Verde, no município de Rio Verde (GO). Foram utilizados 80 leitões mestiços (Landrace $x$ Large White) com peso médio inicial de $9 \mathrm{~kg}$ e idade média de 23 dias. Os animais foram distribuídos em um delineamento inteiramente casualizado, com cinco tratamentos $(18,17,16,15$ e 14\% PB), oito repetições e dois animais por unidade experimental. $\mathrm{O}$ experimento teve uma duração de 42 dias, onde os animais atingiram em média $23 \mathrm{~kg}$.

Condições ambientais de ensaio: Os animais foram alojados em gaiolas metálicas suspensas, com piso ripado e lateral com telas, com comedouro semi-automático e bebedouro tipo chupeta. A sala era de alvenaria com piso de cimento, com janelões de vidro tipo basculante, teto com forro de madeira e telhas de cimento amianto.

A temperatura média no interior da sala foi de $\pm 24^{\circ} \mathrm{C}$, com umidade relativa média de $\pm 78,7 \%$. O Índice de Temperatura de Globo e Umidade (ITGU) calculado no período do experimento foi de 70,4. A temperatura interna da sala foi mantida por meio de um conjunto de seis campânulas elétricas, distribuídas em dois corredores, a aproximadamente $40 \mathrm{~cm}$ do piso, e por dois aparelhos de ar-condicionado de 30.000 BTUs, ligados a um termostato que regulava automaticamente a temperatura da sala como programado. Foram utilizados termômetros de bulbo seco e bulbo úmido, termômetros de máxima e de mínima e termômetro de globo negro, mantidos em uma gaiola vazia no centro da sala, à meia altura do corpo do animal. A temperatura de $24^{\circ} \mathrm{C}$, escolhida para a realização deste trabalho, pode ser caracterizada como uma temperatura de termoneutralidade por estar na faixa considerada ideal para esta categoria animal, segundo Ferreira et al. (2003).

Dietas experimentais: As rações experimentais foram isolisínicas digestíveis (Tabela 1), e os demais aminoácidos foram suplementados para atender as relações estabelecidas por Chung e Baker (1992). As rações experimentais e a água foram fornecidas à vontade até o final do experimento, quando os animais atingiram o peso médio de $23 \mathrm{~kg}$. As sobras de ração foram recolhidas e pesadas semanalmente. O experimento teve duração total de 63 dias, sem período de adaptação.

Ao término do período experimental, os animais foram submetidos a jejum alimentar de 24 horas, sendo um animal de cada unidade experimental abatido por dessensibilização e sangramento. Após o abate, procedeu-se à evisceração para retirada dos órgãos. As análises de matéria seca, proteína e gordura das amostras foram realizadas de acordo com o método descrito por Silva e Queiroz (1996), no Laboratório de Nutrição Animal do Departamento de Zootecnia da FESURV.

Análise estatística: As análises estatísticas das variáveis de desempenho, de taxas de deposição de proteína e gordura nas carcaças e de pesos dos órgãos foram realizadas utilizando-se o procedimento GLM do SAS, versão 6.12 (SMITH; II O 'QUINN; TOKACH, 1997). A soma de quadrados dos tratamentos foi decomposta em contrastes ortogonais, seguindo o modelo estatístico:

$\mathrm{Y}_{\mathrm{ij}}=\mu+\mathrm{E}_{\mathrm{i}}+\varepsilon_{\mathrm{ij}}$

em que: $\mathrm{Y}_{\mathrm{ij}}=$ ganho de peso, consumo de ração, conversão alimentar, taxas de deposição de proteína e gordura e pesos dos órgãos referentes ao nível de proteína i na repetição j; $\mu=$ média geral da característica; $\mathrm{E}_{\mathrm{i}}=$ efeito do nível de proteína bruta $\mathrm{i}$, sendo $i=18,17,16,15$ e $14 \%$ na ração; e $\varepsilon_{i j}=$ erro aleatório associado a cada observação.

Análises nutricionais: A avaliação da possibilidade de redução da proteína bruta da ração com suplementação de aminoácidos foi feita com base nos resultados de ganho de peso, consumo de ração, conversão alimentar, consumos de lisina e energia digestíveis, consumo de nitrogênio $(\mathrm{N})$, eficiência de utilização de nitrogênio para ganho e taxas de deposição de proteína e gordura na carcaça.

\section{Resultados e discussão}

O valor de ITGU (70,4\%), que caracterizou o ambiente de termoneutro, foi similar aos de Ferreira et al. (2003) e Oliveira (1996), que trabalhando com suínos machos castrados de 15 a $30 \mathrm{~kg}$, ambos mantidos em condições de termoneutralidade, obtiveram 69,4 e 70,7\%, respectivamente.

Os resultados de desempenho (ganho de peso, consumo de ração e conversão alimentar), consumos de lisina e energia digestíveis, consumo de nitrogênio, eficiência de utilização de nitrogênio para ganho, relação lisina: proteína bruta e taxas de 
deposição de proteína (TDP) e gordura (TDG) na carcaça dos suínos são apresentados na Tabela 2.

O ganho de peso diário (GPD) não foi influenciado $(\mathrm{p}>0,10)$ pela redução do nível de proteína bruta $(\mathrm{PB})$ da ração. Esse resultado corrobora com aqueles apresentados por Bellego et al. (2001) e Canh et al. (1998), que não verificaram influência da redução da PB sobre o ganho de peso de suínos nesta fase de criação. Da mesma forma, Figueroa et al. (2001) observaram que a proteína bruta da ração pode ser reduzida de 16 para $12 \%$ sem influenciar o GPD dos animais, desde que mantida a relação ideal entre os aminoácidos das rações, o que pode ser obtido com a suplementação de aminoácidos.

Os animais que receberam a ração com menor nível de $\mathrm{PB}$ (14\%) apresentaram GPD de 1,68\% superior àqueles que rece-

Tabela 1. Composição das rações experimentais.

\begin{tabular}{|c|c|c|c|c|c|}
\hline \multirow[t]{2}{*}{ Ingredientes } & \multicolumn{5}{|c|}{ Níveis de proteína bruta (\%) } \\
\hline & 18 & 17 & 16 & 15 & 14 \\
\hline Milho $(7,75 \% \mathrm{~PB})^{1}$ & 67,265 & 63,525 & 59,790 & 56,056 & 52,314 \\
\hline Farelo de soja $(45,5 \% \mathrm{~PB})^{1}$ & 28,192 & 26,625 & 25,059 & 23,494 & 21,926 \\
\hline Amido & 0,490 & 5,300 & 10,130 & 14,930 & 19,780 \\
\hline Fosfato bicálcico & 1,408 & 1,495 & 1,580 & 1,670 & 1,755 \\
\hline Calcário & 0,677 & 0,639 & 0,605 & 0,565 & 0,530 \\
\hline Mistura mineral $^{2}$ & 0,100 & 0,100 & 0,100 & 0,100 & 0,100 \\
\hline Mistura vitamínica ${ }^{3}$ & 0,100 & 0,100 & 0,100 & 0,100 & 0,100 \\
\hline Sal comum 0,250 & 0,255 & 0,260 & 0,267 & 0,272 & \\
\hline $\mathrm{BHT}$ & 0,010 & 0,010 & 0,010 & 0,010 & 0,010 \\
\hline Óleo de soja & 1,000 & 1,000 & 1,000 & 1,000 & 1,000 \\
\hline DL-metionina & 0,014 & 0,043 & 0,072 & 0,100 & 0,129 \\
\hline L-Lisina $\mathrm{HCl}$ & 0,000 & 0,600 & 0,119 & 0,180 & 0,240 \\
\hline L-Treonina & 0,000 & 0,000 & 0,010 & 0,046 & 0,081 \\
\hline Areia lavada & 0,049 & 0,848 & 1,175 & 1,482 & 1,763 \\
\hline Total & 100,000 & 100,000 & 100,000 & 100,000 & 100,000 \\
\hline \multicolumn{6}{|l|}{ Composição calculada $^{4}(\%)$} \\
\hline Proteína bruta & 18 & 17 & 16 & 15 & 14 \\
\hline $\mathrm{ED}$ & 3400 & 3400 & 3400 & 3400 & 3400 \\
\hline Lisina total & 0,964 & 0,957 & 950 & 954 & 938 \\
\hline Lisina dig. & 0,846 & 0,846 & 846 & 846 & 846 \\
\hline Met + Cis dig. & 0,524 & 0,524 & 524 & 524 & 524 \\
\hline Treonina dig. & 0,626 & 0,592 & 567 & 567 & 567 \\
\hline Tripitofano dig. & 0,217 & 0,205 & 193 & 181 & 169 \\
\hline Isoleicina dig. & 0,734 & 0,693 & 652 & 612 & 571 \\
\hline Cálcio & 0,700 & 0,700 & 700 & 700 & 700 \\
\hline Fósforo total & 0,550 & 0,550 & 550 & 550 & 550 \\
\hline
\end{tabular}

${ }^{1}$ Análises realizadas no laboratório de nutrição animal do Departamento de Zootecnia da FESURV; ${ }^{2}$ Conteúdo/kg: 100 g Fe; 10 g Cu; $1 \mathrm{~g}$ Co; 40 g Mn; 100 g Zn; 1,5 g I; 1000 g excipiente q.s.p; ${ }^{3}$ Conteúdo/kg: Vit A - 6.000.000 U; D3 - 1.500.000 UI; E - 15.000 UI; B1 - 1,35; B2 - 48; B6 - 25; Ac pantotênico - 9,355; VitB12 - 20,08; ác fólico - 0,65; biotina - 0,08 g; selênio - 0,39; excipiente q.s.p. -1.000 g; e ${ }^{4}$ Composição calculada segundo Rostagno et al. (1992).

Tabela 2. Resultados de desempenho, energia digestível (ED), consumo de nitrogênio (N), eficiência de utilização de nitrogênio para ganho (EUNG) e taxas de deposição de proteínas e gordura em suínos de 9 a $23 \mathrm{~kg}$ mantidos em ambiente termoneutro.

\begin{tabular}{|c|c|c|c|c|c|c|}
\hline \multirow[t]{2}{*}{ Variáveis } & \multicolumn{5}{|c|}{ Proteína bruta (\%) } & \multirow[t]{2}{*}{ CV\% } \\
\hline & 18 & 17 & 16 & 15 & 14 & \\
\hline Ganho de peso diário $(\mathrm{kg} / \mathrm{d})$ & $0,534^{\mathrm{a}}$ & $0,546^{\mathrm{a}}$ & $0,528^{\mathrm{a}}$ & $0,540^{\mathrm{a}}$ & $0,543^{\mathrm{a}}$ & 12,1 \\
\hline Consumo de ração $(\mathrm{kg} / \mathrm{d})$ & $1,197^{\mathrm{a}}$ & $1,256^{\mathrm{a}}$ & $1,191^{\mathrm{a}}$ & $1,227^{\mathrm{a}}$ & $1,233^{\mathrm{a}}$ & 9,4 \\
\hline Conversão alimentar $(\mathrm{kg} / \mathrm{kg})$ & $1,732^{\mathrm{a}}$ & $1,791^{\mathrm{a}}$ & $1,810^{\mathrm{a}}$ & $1,828^{\mathrm{a}}$ & $1,805^{\mathrm{a}}$ & 6,9 \\
\hline Consumo lisina dig. & $0,988^{\mathrm{a}}$ & $1,044^{\mathrm{a}}$ & $0,981^{\mathrm{a}}$ & $1,101^{\mathrm{a}}$ & $1,101^{\mathrm{a}}$ & 9,4 \\
\hline Consumo de ED (kcal/d) & $3,972^{\mathrm{a}}$ & $4,172^{\mathrm{a}}$ & $3,952^{\mathrm{a}}$ & $4,083^{\mathrm{a}}$ & $4,085^{\mathrm{a}}$ & 9,6 \\
\hline \multicolumn{7}{|c|}{ Taxas de deposição de carcaça } \\
\hline Proteína (kg/d) & $77^{\mathrm{a}}$ & $79^{\mathrm{a}}$ & $72^{\mathrm{a}}$ & $75^{\mathrm{a}}$ & $81^{\mathrm{a}}$ & 9,3 \\
\hline Gordura $(\mathrm{kg} / \mathrm{d})$ & $85^{\mathrm{a}}$ & $91^{\mathrm{a}}$ & $90^{\mathrm{a}}$ & $85^{\mathrm{a}}$ & $87^{a}$ & 14,3 \\
\hline
\end{tabular}

$(\mathrm{p}<0,01)$ Médias seguidas da mesma letra na linha não diferem entre si - Contrastes múltiplos. 
beram a ração com $18 \%$ de $\mathrm{PB}$. Tais resultados corroboram com Ferreira et al. (2003) e Figueroa et al. (2001), que encontraram 1,7 e 1,8 , respectivamente.

O consumo de ração diário (CRD) não foi influenciado ( $\mathrm{p}>0,10)$ pela redução da proteína bruta da ração, todavia os animais que receberam a ração com o menor nível protéico (14\%) apresentaram, em valores absolutos, um CRD 3,01\% superior àqueles que receberam a ração com $18 \%$ de $\mathrm{PB}$. Esses resultados são semelhantes àqueles apresentados por Canh et al. (1998) e Bellego et al. (2001), que não verificaram influência da redução de 16,5 para $12,5 \%$ no nível de proteína bruta da ração. Ferreira et al. (2003) obtiveram o CRD de 2,7\% maior quando utilizaram as mesmas porcentagens desse experimento. Por outro lado, Hansen, Knabe e Burgoon (1993) observaram que rações com $12 \%$ de $\mathrm{PB}$, mesmo suplementadas com aminoácidos, proporcionaram resultados de desempenho inferiores aos obtidos com rações com 16\% de PB. Esses autores concluíram que a redução do nível de $\mathrm{PB}$ deve ser realizada até dois pontos percentuais, para não comprometer o desempenho dos animais.

A conversão alimentar não foi influenciada $(\mathrm{p}>0,10)$ pelos tratamentos utilizados, conforme resultados obtidos por Myer e Bucklin (1996). Porém, divergem aos apresentados por Miller et al. (1996), que verificaram pior conversão alimentar de suínos em crescimento $(24 \mathrm{~kg})$, mantidos em ambiente termoneutro e recebendo dietas com níveis variáveis de proteína (19,1 a 14,6\%) suplementadas com aminoácidos.

Os animais que receberam a ração com 14\% de PB tiveram o consumo de $\mathrm{N}$ reduzido em $14,71 \%$ em relação àqueles que receberam as rações com 17 e $18 \%$ de $\mathrm{PB}(\mathrm{p}>0,01)$, porém, o grupo não diferiu dos demais tratamentos (16 e 15\%). Bellego et al. (2001) e Ferreira et al. (2003) observaram o decréscimo de quase $1 \%$ no consumo de $\mathrm{N}$ em animais que receberam menores quantidades de $\mathrm{PB}$ na ração.

A eficiência de utilização de nitrogênio para ganho (EUNG) aumentou gradativamente $(\mathrm{p}<0,01)$, sendo o maior valor observado com os animais que receberam a ração com $14 \%$ de PB. Os resultados de EUNG obtidos justificam a semelhança dos valores absolutos de deposição de proteína ocorridos nos animais que receberam as rações com 14 e $17 \%$ de $\mathrm{PB}$. Os resultados obtidos estão coerentes com aqueles relatados por Ferreira et al. (2003) e Lopez et al. (1994).
As taxas de deposição de proteína (TDP) e de gordura (TDG) na carcaça não foram influenciadas $(\mathrm{p}>0,10)$ pela redução da proteína das rações. A ausência de efeitos entre tratamentos permitiu deduzir que a ingestão diária de energia atendeu às demandas metabólicas para deposição de proteína e gordura dos animais. Provavelmente este resultado pode ser indicativo de que a retenção de nitrogênio não foi comprometida pela redução do nível de proteína bruta entre os tratamentos. Os resultados obtidos neste estudo são discrepantes com os de Smith, II O'Quinn e Tokach (1997), os quais avaliando a redução da PB em rações para suínos em crescimento, verificaram maior deposição de gordura nos animais que receberam a ração com menor nível de PB. Em revisão sobre o assunto, Kidd (2001) relatou que essa prática não compromete o desempenho dos animais, exceto pela maior deposição de gordura em suínos e de gordura abdominal em frangos de corte, ambos alimentados com rações de baixo teor/nível de proteína bruta.

Os resultados de pesos absoluto e relativo dos órgãos avaliados (rins, fígado, estômago e intestino) estão apresentados na Tabela 3.

Os tratamentos utilizados influenciaram os pesos absolutos de estômago $(\mathrm{p}<0,05)$ e intestino $(\mathrm{p}<0,05)$ e os pesos relativos de estômago $(\mathrm{p}<0,01)$. Não foi observada diferença significativa $(\mathrm{p}>0,05)$ nos pesos absolutos e relativos de fígado e rins.

Os maiores valores obtidos de peso absoluto e relativo de estômago foram observados nos animais que receberam a ração com maior nível de proteína bruta, corroborando com Ferreira et al. (2003) e Keer e Easter (1995) quando trabalharam com leitoas em fase inicial de crescimento até a fase de terminação, verificaram que os animais que receberam a ração com maior nível de PB na ração (19 e 16\%, respectivamente) apresentaram maiores pesos de órgãos, quando comparados aos que receberam ração com menor nível de PB (14 e 12\%). Os maiores valores de pesos absoluto e relativo de estômago observados nos animais alimentados com ração contendo maior nível de $\mathrm{PB}$ não são biologicamente explicados, uma vez que o consumo de ração não foi influenciado.

O nível de $\mathrm{PB}$ da ração para suínos machos castrados de 9 a $23 \mathrm{~kg}$ mantidos em ambiente termoneutro pode ser reduzido de 18 para $14 \%$, sem influenciar negativamente no desempenho do animal. Mas para isso, as rações devem ser devidamente

Tabela 3. Pesos absolutos e relativos dos rins, fígado, estômago e intestino de suínos de 9 a $23 \mathrm{~kg}$ mantidos em ambiente termoneutro.

\begin{tabular}{|c|c|c|c|c|c|c|}
\hline \multirow[t]{2}{*}{ Variáveis } & \multicolumn{5}{|c|}{ Proteína bruta (\%) } & \multirow[t]{2}{*}{$\mathrm{CV}(\%)$} \\
\hline & 18 & 17 & 16 & 15 & 14 & \\
\hline \multicolumn{7}{|c|}{ Peso absoluto (kg) } \\
\hline Fígado & $0,662^{\mathrm{a}}$ & $0,624^{\mathrm{a}}$ & $0,662^{\mathrm{a}}$ & $0,656^{\mathrm{a}}$ & $0,633^{\mathrm{a}}$ & 7,3 \\
\hline Rins & $0,120^{\mathrm{a}}$ & $0,124^{\mathrm{a}}$ & $0,113^{\mathrm{a}}$ & $0,107^{\mathrm{a}}$ & $0,117^{\mathrm{a}}$ & 8,4 \\
\hline Estômago & $0,204^{\mathrm{a}}$ & $0,189^{b}$ & $0,183^{b c}$ & $0,175^{b c}$ & $0,195^{\mathrm{b}}$ & 8,1 \\
\hline Intestino $^{2}$ & $1,064^{\mathrm{a}}$ & $1,023^{\mathrm{a}}$ & $1,029^{\mathrm{a}}$ & $0,941^{\mathrm{b}}$ & $1,082^{\mathrm{ab}}$ & 6,2 \\
\hline Rins & $0,58^{\mathrm{a}}$ & $0,58^{\mathrm{a}}$ & $0,53^{\mathrm{a}}$ & $0,51^{\mathrm{a}}$ & $0,57^{\mathrm{a}}$ & 9,2 \\
\hline Estômago $^{1}$ & $0,98^{\mathrm{a}}$ & $0,87^{\mathrm{b}}$ & $0,88^{\mathrm{b}}$ & $0,83^{\mathrm{b}}$ & $0,94^{\mathrm{b}}$ & 7,8 \\
\hline Intestino & $5,10^{\mathrm{a}}$ & $4,82^{\mathrm{a}}$ & $4,91^{\mathrm{a}}$ & $4,49^{a}$ & $5,17^{\mathrm{a}}$ & 8,1 \\
\hline
\end{tabular}

${ }^{1}(\mathrm{p}<0,01) ; \mathrm{e}^{2}(\mathrm{p}<0,05)$. Médias seguidas de letras distintas na linha diferente entre si, em contrastes múltiplos. 
suplementadas com aminoácidos essenciais limitantes, ou o desempenho dos animais poderá ser afetado de alguma forma.

\section{Agradecimentos}

Os autores agradecem à Agropecuária Boa Vista, pelo apoio financeiro e aos Srs. Aires Neto Campos Ferreira e Silvio Martins de Paiva, pelo conhecimento dividido.

\section{Referências bibliográficas}

ANDRIGUETTO, J. M. et al. Nutrição Animal. 2a ed. São Paulo: Nobel, 1983. 425 p.

BELLEGO, L. L. et al. Energy utilization of low- protein diets in growing pigs. Journal of Animal Science, Savoy, v. 79, n. 5, p. 1259-1271, 2001.

CANH, T. T. et al. Dietary protein affects nitrogen excretion and ammonia emission from slurry of growing-finishing pigs. Livestock Production Science, v. 56, n. 3, p. 181-191, 1998.

CHUNG, T. K.; BAKER, D. H. Ideal amino acid pattern for 10 kilogram pigs. Journal of Animal Science, v. 70, n. 10, p. 3102-3111, 1992. Savoy.

FERREIRA, R. A. et al. Redução da Proteína Bruta da Ração para suínos Machos castrados dos 15 aos $30 \mathrm{~kg}$ mantidos em termoneutralidade. Revista Brasileira de Zootecnia, Viçosa, v. 32, n. 6, p. 1639-1646, 2003.

FIGUEROA, J. L.; LEWIS, A. J.; MILLER, P. S. Nitrogen balance and growth trials with pigs fed low-crude protein, amino acid supplemented diets. Nebraska Swine Report, Lincoln, p. 26-28, 2000.

FIGUEROA, J. L. et al. Valine, isoleucine, and histidine supplementation of low protein, amino acid-supplemented diets for growing pigs. Nebraska Swine Report, Lincoln, p. 23-26, 2001.

HANSEN, J. A.; KNABE, D. A.; BURGOON, K. G. Amino acid supplementation of low protein sorghum-soybean meal diets for 20 to 50 kilogram swine. Journal of Animal Science, Savoy, v. 71, n. 2, p. 442-451, 1993.

KERR, B. J.; EASTER, R. A. Effect of Reduced Protein, Amino AcidSupplemented Diets on and Energy Balance in Grower Pigs. Journal of Animal Science, Savoy, v. 73, n. 10, p. 3000-3008, 1995.

KIDD, R. H. Interretionsnhips between dietary protein level, energy intake, and nitrogen retention in pigs. Journal Animal Science, Savoy, v. 71, n. 9, p. 2450- 2456, 2001.

LOPEZ, J. et al. The effects of diets formulated on an ideal Protein Basis on Growth Performance, Carcass Characteristics, and Thermal
Balance of Finishing Gilts Housed in a Hot, Diurnal Environment. Journal of Animal Science, Savoy, v. 72, n. 9, p. 367-379, 1994.

OLIVEIRA, R. F. M. Efeito do nível de energia digestível e da temperatura ambiente sobre o desempenho e sobre parâmetros fisiológicos e hormonal de suínos dos 15 aos $30 \mathrm{~kg}$. Viçosa, MG: Universidade Federal de Viçosa, 1996. 139 p. Tese (Doutorado em Zootecnia) - Universidade Federal de Viçosa, 1996.

MILLER, P. S. et al. Performance of growing-finishing pigs consuming diets formulated on an ideal protein (first four limiting amino acids) basis. Nebraska Swine Report, Lincoln, p. 27-30, 1996.

MYER, R. O.; BUCKLIN, R. Influence of a hot and humid rearing environment and plane of nutrition on performance and carcass lean content of growing-finishing swine. Journal of Animal Science, Savoy, v. 73, n. 2, p. 290, 1995.

PARSONS, C. M.; BAKER, D. H. The concept and use of ideal proteins in the feeding of no ruminants. In: Simpósio Internacional de não Ruminantes, Maringá, Paraná: SBZ, 1994. p. 119-128.

PATIENCE, J. F. A review of the role of acid-base balance in amino acid nutrition. Journal of Animal Science, Savoy, v. 68, n. 2, p. 398408, 1990.

PERDOMO, C. C. Considerações sobre o condicionamento ambiental na produção de suínos. In: BIAGI, J. D. et al. (Ed.). Simpósio sobre Nutrição Animal e Tecnologia da Produção de Rações, Campinas, São Paulo: Colégio Brasileiro de Nutrição Animal, 1998. p.147-154.

PFEIFFER, A. et al. The influence of protein intake on water balance, flow rate and apparent digestibility of nutrients at the distal ileum in growing pigs. Livestock Production Science, v. 44, n. 2 p. 179187, 1995.

SAS. Statistical Analyses System. SAS System for Windows, release 6.12. Cary: 1996. CD-ROM.

SILVA, D. J.; QUEIROZ, A. C. Análise de Alimentos: métodos químicos e biológicos, $3^{\mathrm{a}}$ ed, Viçosa : UFV, 2002. 235 p.

SILVA, I. J. O. Sistemas naturais e artificiais do controle do ambiente climatização. In: SIMPÓSIO DE AMBIÊNCIA E QUALIDADE NA PRODUÇÃO INDUSTRIAL DE SUÍNOS, 1999, Anais...Piracicaba, São Paulo: Fundação de Estudos Agrários “Luiz de Queiroz", 1999, p. 81-111.

SMITH, J. W.; II O'QUINN, P. R.; TOKACH, M. D. Effects of lowprotein, amino acid fortified diets, formulated on a net energy basis, on the growth performance and carcass characteristics of finishing pigs. Swine Day, v. 1, n. 1 p. 85-89, 1997. 